\title{
Avaliação na educação física escolar: tensões para além das epistemologias $^{\mathrm{a}}$
}

http://dx.doi.org/10.11606/1807-5509201700040819

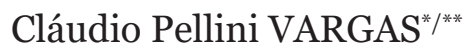

*Universidade Federal de Juiz de Fora, Juiz de Fora, MG, Brasil.

${ }^{* *}$ Centro Universitário Estácio de Sá, Campus Juiz de Fora, Juiz de Fora, MG, Brasil.

\section{Resumo}

0 objetivo do trabalho consiste em identificar tensões que perpassam o tema avaliação na Educação Física escolar, enaltecendo contrastes e semelhanças existentes entre as práticas de professores. $\mathrm{Na}$ estrutura, apresenta sintese epistemológica de Boaventura Santos, argumenta sobre a fragilidade da avaliação fundamentada na modernidade e apresenta revisão teórica sobre o tema, problematizando a forma burocrática de sua realização ao tratar da "cultura corporal". Na discussão, utiliza entrevista semiestruturada aplicada a três professores de EF de escolas públicas, abordando suas experiências na prática avaliativa. Define categorias de análise do conteúdo: ambivalência e subjetividade. Apresenta tensões fundamentais e sustenta que as avaliações burocráticas impedem o conhecimento-emancipação defendido por Santos. Conclui destacando a importância da dimensão axiológica da área, posicionandose a favor da autoavaliação como fomento a emancipação discente.

Palavras-chave: Cultura Corporal; Conhecimento; Modernidade; Escola; Boaventura de Sousa Santos.

\section{Introdução}

A avaliação tem sido entendida e tratada, [lamentável e] predominantemente, por professores e alunos para: a) atender as exigências burocráticas expressas em normas da escola; b) atender a legislação vigente;

c) selecionar alunos para competiçôes e apresentaçôes [...]. Geralmente é feita pela consideração da presença em aula, sendo este o único critério de aprovaçáo e reprovação, ou então, reduzindo-se a medidas de ordem biométrica: peso, altura etc., bem como de técnicas: execução de gestos técnicos, "destrezas motoras", "qualidades físicas", ou, simplesmente, não é realizada ${ }^{1}$ (p. 98-9).

$\mathrm{Na}$ contemporaneidade, a avaliação no âmbito escolar parece caminhar por entre as diversidades das lógicas existentes, estando no cerne das contradiçóes do sistema educativo, na articulação das escolhas e seleçôes, e no reconhecimento e negação das desigualdades, conforme explica Perrenoud ${ }^{2,3}$. Sendo parte de constante reflexão sobre as ações dos indivíduos, a avaliação constitui um processo que se aplica a muitas práticas e é auxiliada por muitas ciências, dentre as quais as educativas, que parecem ter maior relevância. Como o processo avaliativo não pode ser reduzido a questóes meramente técnicas, as teorizaçóes educacionais permeadas pelas humanidades ganham elevada importância quando tratamos da complexa luta objetiva e subjetiva do avaliar o outro.

Assim posto, problematizo neste trabalho questóes sobre epistemologia e avaliação na Educação Física (EF) escolar diante de sua própria crise de identidade ${ }^{4-6}$, e tendo em vista a crise da modernidade, a qual é entendida nas perspectivas epistemológicas de BAUMAN ${ }^{7}$ e SANTOS ${ }^{8-10}$, ou seja, período no qual a racionalidade exerceu forte influência na construção do pensamento ocidental.

O objetivo central consiste em identificar se e que tensóes perpassam o campo avaliativo da EF escolar, enaltecendo possíveis contrastes e semelhanças existentes entre as práticas dos professores nas três esferas públicas (municipal, estadual e federal). De forma mais ampla, busco mitigar lacunas da 
discussão específica sobre avaliação, relacionadas aos professores de EF inseridos no cotidiano escolar. Parece-me um tanto negligenciado o debate sobre a temática. Conforme Santos e Maximiano ${ }^{11}$, o número de pesquisas específicas sobre avaliação na EF escolar parece ser insuficiente:

trabalhos do tipo estado da arte [...] têm demonstrado um reduzido número de pesquisas sobre avaliação na Educação Física. Santos (2002) e Macedo (2011), ao tomarem como fonte os periódicos e congressos científicos da área no período de 1930 a 2010, evidenciam a existência de quarenta artigos que tratam dessa temática, sendo que desses apenas sete mergulham no cotidiano escolar. (p. 884)

$\mathrm{Na}$ estrutura, primeiramente apresento uma síntese epistemológica sobre as ideias de SANTOS $^{8-10}$, que orientam os pressupostos da investigaçáo e relaciono o contexto da $\mathrm{EF}$ a tais compreensōes. A seguir, argumento sobre a fragilidade da avaliaçáo na área, já que ela não apresenta uma sustentabilidade epistemológica a si própria nos parâmetros da modernidade e apresento revisão teórica sobre o tema. Neste sentido, considero o embate entre questôes objetivas e subjetivas que permeiam o processo avaliativo oriundo da modernidade e problematizo a forma burocrática de realizá-lo. A seguir, utilizome de uma entrevista semiestruturada aplicada a três professores de EF de escolas públicas na cidade de Juiz de Fora (MG), um em cada âmbito: federal, estadual e municipal, abordando suas longas trajetórias e suas experiências com a avaliação. $\mathrm{Na}$ discussão, apresento as tensôes pedagógicas e epistemológicas identificadas, as quais emergem fundamentalmente das ambivalências das falas e do distanciamento existente entre as práticas avaliativas, os critérios que permeiam todo o processo e o cenário diverso epistemológico atual. Destaco, por fim, a necessidade de se atribuir status a área por meio de avaliaçōes certificativas como um problema que precisa ser superado, ressalto a importância da dimensão axiológica da EF e posiciono-me a favor da prática da autoavaliaçáo como fomento a emancipação discente.

\section{Justificativas epistemológicas da investigação}

Torna-se imperioso apresentar uma breve síntese epistemológica da teoria que norteia o trabalho. Trato das reflexôes de SAntos $^{8-10}$, as quais se constituem como base dos pressupostos desta investigação, retratando condições teóricas atuais que se relacionam a ideia de conhecimento na modernidade, e que, naturalmente, criam condiçôes sociológicas que recaem sobre a escola, os currículos e a avaliação. Tomo por referência também as reflexôes de Inês Barbosa Oliveira ${ }^{12}$, estudiosa de Boaventura Santos, quem contribui com várias interpretações de sua epistemologia para a área de Educação. Tenho, pois, a intenção de avançar e criar conexóes do pensamento do autor com o cotidiano escolar da EF, em especial com as avaliaçôes reguladoras ou certificativas ${ }^{2}$.

Convém assinalar que, na medida em que entendo que o paradigma emergente "pós" é aberto ao diálogo com inúmeras teorias no contexto de diversidade epistemológica contemporâneo, parece-me plausível poder utilizar a própria teoria crítica, como o Movimento Renovador, no interior epistemológico deste debate. Nesse sentido, acentuo o diálogo entre o paradigma vigente e o paradigma emergente. Ora, Boaventura Santos parece ser um intelectual que admite a ideia de pós-modernidade, mas que se mantém com os "olhos fixos" na modernidade, assim como Bauman, utilizado mais adiante na definição das categorias, é um teórico moderno que analisa o pós-moderno.

Em outras palavras, Boaventura Santos se apropria da própria racionalidade para elaborar sua análise crítica sobre os limites da racionalidade moderna, criando "novas racionalidades". O "pós" defendido pelo autor parece ter um sentido diferente nas suas rupturas com projeto moderno, se comparado, por exemplo, aos ideais "relativistas" defendidos por intelectuais inspirados em Nietzsche, e com as quais não coaduno. Não tenho, sob nenhuma hipótese, a intenção de negar as conquistas oriundas do pensamento moderno, mas sim problematizar suas "fronteiras". Nas palavras de SANTOS ${ }^{8}$, o "projecto sócio-cultural de modernidade é [...] rico, capaz de infinitas possibilidades e, como tal, muito complexo e sujeito a desenvolvimentos contraditórios" (p. 77).

Nessa esteira epistemológica de inúmeras controvérsias, NeIra e Nunes ${ }^{13}$ sustentam que a concepção "pós" - a mesma que exponho neste trabalho - amplia visóes, agrega novos conceitos, reinterpreta outros e redesenha o presente olhando criticamente para o passado e para o futuro simultaneamente. Em suas palavras:

"pós" não é aqui entendido como uma localização no tempo [...], não é simplesmente uma concepção que surge após o pensamento crítico; tampouco é entendido como um movimento de oposição [...]. Em vez disso, o termo "pós" expressa uma reflexão sobre o objeto em estudo que amplia o modo de 
compreendê-lo. "Pós" é ir além. Além significa uma distância espacial que ultrapassa qualquer imposição de limites. [...] Ir além de si é a possibilidade de retornar com novos olhares, revisando e reconstruindo as condiçóes sociais e políticas do presente (p. 136).

Avançando na discussão, a primeira condição de SAntos $^{10}$ se relaciona a ideia de que o aprofundamento do conhecimento científico resulta na fragilidade de sua estrutura. Apoiado na ruptura que Einstein e Heisenberg causaram no universo de Newton por meio da teoria da relatividade e dos teoremas da incerteza, Santos explica a constante interferência estrutural que existe entre o sujeito e o objeto analisado, o que reflete numa nova compreensão sobre produção "científica" do conhecimento.

Um segundo ponto a ser refletido, diz respeito à formalidade das expressóes de mediçóes, o que traz impacto direto sobre a avaliação. $\mathrm{O}$ autor (idem) sustenta que os recentes teoremas sobre a impossibilidade mostram que, mesmo seguindo à risca as regras da lógica, é possível formular ideias propositivas que não se podem demonstrar e, ao mesmo tempo, refutar. Assim, depreende-se a ideia de que qualquer forma de rigor se relaciona com critérios de seletividade, ou seja, de escolha.

Uma terceira problemática fundamental trata da legitimidade do cientificismo moderno. Boaventura explica, amparado nos recentes avanços da Física, que a evolução dos sistemas ocorre por flutuaçóes de energia que desencadeiam reaçóes não-lineares que transformam irreversivelmente o sistema anterior por meio da auto-organização. Em suma, tal evolução seria um produto de uma história.

Ora, se o rigor epistemológico da modernidade é estruturalmente limitado, os resultados de análises amparadas neste rigor também o serão. Com efeito, pesquisar nas ciências sociais passa a ser um desafio ainda maior, na medida em que tais ideias nos permitem recolocar as formas de se "olhar" a escola, a produção do conhecimento e a avaliação das aprendizagens, afastando-nos da forma única e positivista que ainda domina o cenário. A ideia vem provocando reformulaçóes intensas no ideário pedagógico ${ }^{12}$ devido a alguns desdobramentos sociológicos dessa reflexão, os quais explico a seguir.

O mais fundamental relaciona-se ao fato de que as transformações epistemológicas mencionadas são oriundas dos próprios cientistas, os quais passaram a nutrir interesse profundo pela Filosofia e pela
Sociologia, antes relegadas aos "guetos" da ciência moderna no fim do Século XIX. Para SAnTos ${ }^{8,9}$, a intensa dificuldade de se avançar com as formas unilaterais de pesquisa oriundas da modernidade, levou estudiosos a buscar complementos no conhecimento sobre o conhecimento, o que leva a ideia do "olhar a si mesmo" e do conhecer a si próprio. É como se a análise da cultura, da educação e da sociedade, antes subestimada, passasse a ocupar um lugar de maior destaque na reflexão epistemológica contemporânea.

Um segundo ponto diz respeito ao conteúdo do conhecimento científico e daquilo que se avalia a partir dele. $\mathrm{O}$ autor afirma que o conhecimento científico da modernidade é reduzido e que não se abre para outros saberes da natureza, automatizando-a. Trata-se do rigor científico ancorado no rigor da matemática, o qual está essencialmente voltado à quantificação e que afirma mais a personalidade do cientista em detrimento da personalidade da natureza. Para Santos, tal rigor nos faz perder de vista a riqueza do mundo e reprime a busca pelo valor humano. Assim, a ideia de rigor da modernidade retira das práticas sociais sua força axiológica e política, aspectos fundamentais nas práticas corporais da EF e que, para Santos, são indissociáveis das de ordem epistemológica.

Como desdobramentos da reflexão, conforme sustenta OLIVEIRA ${ }^{12}$, surgem situaçōes teóricas mais imediatas em relação à epistemologia herdada da modernidade, acentuadas por Santos e que precisam ser consideradas, como: (1) a necessidade de uma nova conceituação da ciência e do seu sentido em relação ao que circula na sociedade; (2) a reflexão hermenêutica responsável sobre o que a ciência constrói como objeto, rompendo com dogmas; (3) os resultados dessas novas interpretaçóes, os quais devem ser entendidos como uma pedagogia pragmática de ciência, ou seja, as consequências subjetivas produzidas na sociedade também são fundamentos que justificam as próprias reinterpretaçóes; (4) a diversidade de análises e avaliaçóes dos resultados de uma prática científica sobre a sociedade e sobre grupos acadêmicos, considerando o fato das disputas por verdade historicamente realizadas; e (5) o cuidado nas articulaçóes ou conexôes retóricas dessa pedagogia pragmática aos discursos tradicionalmente científicos.

A partir de todo esse contexto, SANTOS $^{9}$ explica que toma por referência de paradigma cultural da modernidade duas noçóes essenciais: conhecimentoregulação e conhecimento-emancipação. Em suas palavras: 
O conhecimento-emancipação é uma trajectória entre um estado de ignorância que designo por colonialismo e um estado de saber que designo por solidariedade. O conhecimentoregulação é uma trajectória entre um estado de ignorância que designo por caos e um estado de saber que designo por ordem. [...] Nos termos do paradigma da modernidade, a vinculação recíproca entre o pilar da regulação e o pilar da emancipação implica que estes dois modelos se articulem em equilíbrio dinâmico. Isto significa que o poder cognitivo da ordem alimenta o poder cognitivo da solidariedade, e vice-versa (p. 78).

De fato, a intenção era esse equilíbrio, mas tomando como pressuposto fundamental que, na modernidade, a racionalidade cognitivoinstrumental expandiu-se sobre as sociedades de tal maneira que as demais racionalidades (moralprática e estético-expressiva) ficaram à margem, o conhecimento-regulação oprimiu o conhecimentoemancipação. Com o desequilíbrio, os estados de saber se inverteram. Explica o autor, sustentandose nas matrizes históricas da formação do Estado Liberal e nas teorias do Contrato Social ${ }^{8}$, que os indivíduos passaram a identificar a solidariedade como algo próximo do caos e o colonialismo como ideia de ordem?

Para SAntos", é "esta a situação em que nos encontramos e é dela que urge sair. E o caminho não pode ser senão o de reavaliar o conhecimentoemancipaçáo e conceder-lhe a primazia sobre o conhecimento-regulação" (p. 79). Assim, parece-me claro, a partir destes pressupostos, a necessidade de novas posturas didáticopedagógicas no interior escolar. Urge deixarmos que o conhecimento-emancipação se torne nova hegemonia de saber e, simultaneamente, que aceitemos o caos por meio de uma "negligência relativa do conhecimento-regulação" (p. 79). $\mathrm{Na}$ medida em que as teorias do caos já são entendidas como conhecimento no próprio cerne das ciências físicas modernas, parece-me plausível a mesma compreensão no âmbito das humanidades, ainda que Santos também problematize essa separação entre as ciências.

Apresento assim, o questionamento que me move nessa escrita: se subvertermos o aspecto burocrático e regulador da avaliação na EF escolar, trocando-o pela ideia de sua prática sem a expectativa das notas que segreguem os alunos na escola em categorias de sucesso ou fracasso, os alunos (e professores) possuirão mais potencial para se desenvolver? A ausência de quantificaçóes será capaz de contribuir para um distanciamento das hierarquias de excelência (e exclusão) oriundas da modernidade ${ }^{2}$ ? Favorecer-se-á, dessa forma, um maior espaço para o tratamento da solidariedade? Chegar-se-á a um maior desenvolvimento da cooperação, em detrimento da rivalidade, da técnica, do rendimento e da eficiência, vistos pela EF moderna como caminhos únicos de sucesso? Essas me parecem questóes que precisam ser examinadas e que justificam este trabalho.

\section{A avaliaçáo em EF na diversidade epistemológica atual: uma breve revisão teórica}

Em consonância também com pesquisas no campo epistemológico da EF e da avaliação na escola, sustento que as novas formas de avaliação a serem desenvolvidas nos próximos anos - essencialmente no campo escolar - deverão envolver um processo que represente maior e melhor articulação teórica entre diferentes visóes epistemológicas e didáticometodológicas.

Assim, e para melhor localização do debate sobre avaliação, apresento alguns trabalhos que colaboram com a temática. SACRISTÀN ${ }^{14}$, por exemplo, sustenta que a avaliação expressa um juízo de valor, por parte do professor, direcionando-o para uma decisão a partir da coleta de determinados indícios. LuCKesI ${ }^{15}$ acrescenta que a avaliação não possui um fim em si mesma, ela norteia açóes que buscam atingir resultados previamente definidos, as intencionalidades. Perrenoud ${ }^{2}$ sustenta limitaçóes no processo moderno da avaliação. Ela não é um objetivo em si mesma, mas tem se apresentado como um meio de verificar se os alunos adquiriram os conhecimentos previamente escolhidos e determinados no currículo. GatTI ${ }^{16}$ contribui e trata de algumas questóes básicas sobre o "pensar a avaliação" na contemporaneidade: (1) qual perspectiva avaliativa se assume ao desenvolver uma avaliação de natureza educacional? (2) O que se entende por qualidade? (3) Qual o significado atribuído ao desenvolvimento profissional? A autora apresenta perspectivas diferentes em processos avaliativos, o que determina atitudes e impactos. Levanta o problema e os dilemas na conceituaçáo do que seja qualidade docente, lembrando que o trabalho docente é diferenciado de outros focos de trabalho, uma vez que envolve um alto grau de subjetividade. 
Já no campo da EF escolar, alguns trabalhos surgem no cenário educacional e destacam a falta de critério por parte dos docentes que avaliam. TENóRIO et al. ${ }^{17}$ realizam relevante discussão acerca do binômio intencionalidade-avaliação articulada ao campo curricular da EF na regiáo sudeste, denunciando suas fragilidades. Para os autores, "há falta de clareza teórica quanto à forma de organizar as intencionalidades, se por objetivos, se por competências/habilidades" (p. 553). FrIzzo ${ }^{18}$ identificou que a principal categoria de análise da organização do trabalho pedagógico é o par dialético objetivo e avaliação, pois essa é quem direciona e controla a formação do alunado na escola, sendo determinante na relação entre os sujeitos (alunado e professorado) e o conhecimento.

Melo ${ }^{19}$ mostrou que os professores, ao escolherem os critérios e instrumentos de avaliação, destacaram preferência para a observação da participação e envolvimentos em aula, bem como demonstraram a preocupação em diversificar as técnicas de avaliação. Esses sinais evidenciaram mudanças na prática avaliativa dos professores investigados, pois demonstraram que a avaliação não mais é planejada sob o foco da medição e quantificação de resultados de desempenhos físicos. Entretanto, durante a pesquisa, observouse pouca diversificação dos critérios de avaliação e escassez de estratégias para avaliar de maneira coerente com o processo de ensino e aprendizagem. RAMIRO $^{20}$ indica uma ausência de discussão sobre a avaliação no processo formativo inicial e continuado dos educadores, o que resulta em entendimentos relativos e confusos sobre os critérios e instrumentos avaliativos. Constata também, que existe prevalência da avaliação por meio da participação e observação.

Numa perspectiva cultural, EsCUDERO ${ }^{21}$ afirma que a avaliação é compreendida pelos professores como um texto em construção, como uma produção escrita baseada em informaçóes sobre a ação educativa: produçóes dos alunos, pesquisas realizadas tanto pelos professores como pelos alunos e vivências corporais, distanciando-se do viés classificatório e excludente. $\mathrm{Na}$ mesma esteira, VARGAS $^{22}$ explica que, por possuírem uma gama de movimentos carregada de múltiplos sentidos, as brincadeiras, os esportes, as danças, entre outras manifestações concebidas como textos corporais, constituem-se em formas de expressão, produção e reprodução de significados culturais. Assim, tais significaçóes precisam ser analisadas e avaliadas de uma forma diferenciada na escola, considerandose as múltiplas construçôes da linguagem e não apenas aquela socialmente construída pela modernidade.

Feito um breve mapeamento sobre pesquisas recentes em avaliação na EF, e para iniciar a reflexão, parto da problemática levantada por SouZA JúNIOR ${ }^{23}$, afirmando que:

Muitos professores se queixam de que a atual Lei de Diretrizes e Bases da Educação Nacional LDB (Lei 9.394/96) causou grande impacto na Educação Física, no que diz respeito à avaliaçấo. Geralmente se referem ao desprestígio da Educação Física diante do aluno, devido à impossibilidade de sua reprovação neste componente curricular (p. 202).

De fato, o problema apontado parece permanecer na contemporaneidade da área. Concordo com o autor no que tange aos professores que se apegam ao desprestígio, à falta de legitimidade do campo no interior escolar - reforçado pela LDB - para argumentarem sobre as dificuldades vivenciadas na avaliaçáo da EF escolar. Para além disso, os discentes escolares também vivem sob a "pressáo" de rendimentos numéricos oriundos de outras disciplinas para atenderem a demanda mercadológica ou mesmo a aprovação direta em concursos e vestibulares. Ainda segundo SOUZA JÚNIOR ${ }^{23}$ :

Como a atual LDB estabelece a carga horária do ano letivo pelo somatório dos componentes curriculares em, no mínimo, 800 horasaula (h/a)/a, a serem cumpridas em 200 dias letivos; como ela dá ao aluno o direito de faltar até o limite de $25 \%$ dessa carga horária anual; e como a Educação Física tem como critério de avaliação preponderante, ou talvez até exclusivo, a apuração da assiduidade, ou seja, o controle da frequência - mesmo que os alunos faltem a todas as aulas de Educação Física, o que equivale aproximadamente a $80 \mathrm{~h} / \mathrm{a}$ anuais, considerando a periodicidade de duas aulas semanais, que é a mais comum - eles não serão impedidos de serem promovidos para a série, etapa ou ciclo seguinte por esse resultado de avaliaçáo em Educação Física (p. 202).

Essa problemática traz a questão da igualdade entre a Educaçáo Física e os demais componentes curriculares. A equiparação apontaria para uma luta na busca pela legitimidade da Educação Física na escola, e que náo deveria, porém, significar que a disciplina aprove ou reprove o aluno. $\mathrm{O}$ resultado 
dessa avaliação deve processar-se na articulação entre objetivos, conteúdos e metodologias. Continua o autor $^{23}$, explicando que a promoção ou retençáo [do aluno] deve ser o último aspecto da avaliaçáo, e não objeto de desejo de um componente curricular na construção de sua legitimidade.

Nessa esteira de pensamento, emerge uma questão talvez mais fundamental do que própria reflexão exposta. Ora, antes da área de EF interrogar seus alunos, ou mesmo pensar em aprovar ou reprovar segundo a ideia da modernidade, sustento que nós - os professores - devemos questionála: a partir de qual ponto de vista o aluno será avaliado? Tal questionamento se baseia no fato de que a área continua não possuindo uma sustentabilidade epistemológica que lhe possibilite a tarefa de uma única forma avaliativa. O campo em si, quando visto como disciplina escolar ou acadêmica nos padróes modernos, é frágil por não elaborar instrumentos avaliativos partindo de sua própria produção do conhecimento, portanto, não questiona a realidade investigada com métodos desenvolvidos por sua própria forma de enxergar o mundo. A própria ideia de cultura corporal, a qual defendo como importante avanço da área, e que permeou o debate nos últimos 25 anos, parece também carregar em seu bojo ambivalências e inúmeras formas de interpretação. Que vem a ser cultura? Portanto, que avaliaçôes escolares poderiam traduzir tamanha diversidade de entendimentos? Não reivindico aqui que a EF encontre uma identidade ou tenha uma particularidade, e até suponho isso improvável. Defendo, apenas, que ela não responde às expectativas da modernidade, portanto, náo me parece prudente que ela avalie seus alunos conforme orienta a modernidade.

Revisitando a crise epistemológica da $\mathrm{EF}^{4-6}$, sustento sua histórica fundamentação ancorada na dicotomia mente/corpo. Tal dualismo incentivou a sociedade a pensar que deveria ser necessário educar as duas partes de tal divisão. Então, o pensamento racionalista do século XX, na sua ânsia pela ordem excessiva, do controle e da padronização de comportamentos, das divisóes e segregaçôes, sugeriu o entendimento de que a escola foi uma das instituiçóes que promoveu uma possibilidade formal de educar mente e corpo separadamente. Essa formalização, assumida pela Escola, para além de algumas contribuiçóes ou da própria pretensão de conseguir educar a mente e o corpo, parece também ter fomentado dificuldades, como as monoculturas e o bloqueio das possibilidades de emancipações sociais ${ }^{8,9}$, observadas nas dependências metodológicas de ensino, nos currículos apenas prescritivos, na burocracia paralisante e nos intensos controles avaliativos.

A EF escolar, constituindo-se numa área pedagógica de intervenção ${ }^{4}$, e que se apropria da ciência produzida em outras áreas do saber, é campo oportuno para se problematizar as necessidades avaliativas numéricas, oriundas essencialmente do pensamento moderno, e me parece rica para contribuir no direcionamento de reinterpretaçóes do campo da cultura e ainda, para o conhecimentoemancipação. Se ela não é uma ciência nos padrōes modernos, se ela náo produz um conhecimento próprio nestes padróes, e se ela se apropria da cultura corporal como seu objeto, penso que propor modelos avaliativos quantitativos, os quais se fundamentem numa forma específica de apropriaçáo do conhecimento ou de compreensão dessa cultura, significa desconsiderar a diversidade epistemológica presente na atual fase da história humana ${ }^{8,9}$.

Reconhecer essa diversidade, entretanto, não implica uma postura pessoal de análise relativista, a qual validaria qualquer discurso e também não significa sob nenhuma hipótese, a ideia de retórica não argumentada, bem tratada por Lovisolo et al. ${ }^{24}$ Tenho a intenção de posicionar-me criticamente diante das entrevistas realizadas, apoiando-me numa dialética reflexiva, reconhecendo minhas subjetividades enquanto sujeito também inserido no processo investigativo, as quais impactam inequivocamente na análise, assim como explicado no contexto epistemológico descrito até aqui.

\section{Método}

Para sustentar a discussão, realizo uma entrevista semiestruturada, a qual foi aplicada a três professores de EF de escolas públicas nas três redes: federal, estadual e municipal, todas localizadas na cidade de Juiz de
Fora (MG). As escolas públicas foram escolhidas de forma aleatória no contexto de suas esferas públicas, considerando que existem 102 municipais, 49 estaduais e 03 federais na cidade citada. 
Nas escolas federal e estadual, havia cinco professores de EF licenciados que exerciam o cargo de Professor da Educação Básica e na municipal havia quatro. Os entrevistados foram escolhidos atendendo a três critérios fundamentais: (1) possuir maior tempo de docência na instituição que os demais professores com os quais trabalham, o que sustento ser indicativo de maior conhecimento da cultura escolar local e de certa estabilidade nos procedimentos didáticos; (2) maior tempo de formação e docência que o entrevistador, fato que traz relevância no que diz respeito às longas trajetórias dos entrevistados; e (3) não possuir titulação Stricto Sensu, condição que me leva a compreender existir um maior afastamento das teorizaçôes metodológicas, o que favorece mais espontaneidade e revelaçóes subjetivas durantes as falas.

Priorizei professores possuindo, entre eles, praticamente o mesmo de tempo de formação/ atuação na Educação Básica e foram apenas os três que atendiam simultaneamente aos critérios destacados. Assim, ressalto que o tempo médio de trabalho docente dos entrevistados era de vinte anos (todos formados em meados da década de 1990), fato que me parece suficiente para que possam ter desenvolvido também uma avaliação mais criteriosa sobre o próprio trabalho pedagógico em sua subárea de atuação na EF e sobre seus saberes, estes compreendidos nas teorias de MAURICE TARDIF ${ }^{25}$.

$\mathrm{O}$ trabalho consiste, essencialmente, num corte de cunho qualitativo de pesquisa. Tomo por base interpretativa a análise de conteúdo e busco enfatizar os três setores da esfera pública na intenção de identificar as semelhanças e enaltecer os contrastes percebidos nas práticas didático-avaliativas dos professores em cada âmbito, mas sem qualquer pretensão de comparar os sistemas. Outrossim, almejo dar visibilidade as dificuldades enfrentadas pelos docentes.

Em síntese, busquei a autenticidade das falas de professores experientes, que vivenciam o "chão da escola", que são efetivos (estabilizados) em seus cargos públicos (considerando que docentes "contratados" ou "temporários" parecem demonstrar maior receio ao serem questionados sobre seu trabalho) e que não compreendem com maiores detalhes os "pormenores" de uma investigação científica. Por fim, convém ainda informar que os professores das redes Estadual e Municipal foram graduados em universidades públicas federais do estado de Minas Gerais, enquanto o da rede federal graduou-se em instituição privada no estado do Rio de Janeiro.
Iniciei as entrevistas a partir de um questionário semiestruturado: (1) Conceitue EF com suas palavras; (2) Como você compreende, de um modo geral, o processo de avaliação na escola? (3) Como você compreende o processo de avaliação na $\mathrm{EF}$ escolar? (4) Você avalia seus alunos na EF escolar? Em caso negativo, explique o porquê. Em caso positivo, explique detalhadamente o processo; e (5) Nos últimos anos, parece ser um entendimento comum a percepção de que os alunos estão se afastando das práticas de EF na escola. Você considera que isto esteja ocorrendo? Em caso afirmativo, a quais motivos você atribui tal evasão?

Os encontros - gravados - duraram em média 60 minutos e todo processo aconteceu com a autorização dos entrevistados. Os recortes das entrevistas foram agrupados por razóes didáticas, visando facilitar o entendimento do leitor. Por questóes éticas, todos os nomes foram preservados, adotando-se PF para Professor da Escola Federal; PE para professor da Escola Estadual; PM para professor da Escola Municipal; e E para entrevistador. Os recortes das respostas não são aleatórios, e buscaram destacar os pontos mais relevantes da discussão.

Isto posto, para a análise de conteúdo foram determinadas duas categorias essenciais. A primeira, definida por ambivalência, segue os parâmetros de BAUMAN $^{26}$ :

Uma desordem específica da linguagem, uma falha da função nomeadora (segregadora) que a linguagem deve desempenhar. O principal sintoma de desordem é o agudo desconforto que sentimos quando somos incapazes de ler adequadamente a situação e optar entre açôes alternativas. [...] A ambivalência é [...] o alter ego da linguagem [...], sua condição normal (p. 9).

A segunda trata da compreensão da expressão subjetividade (dos professores) a partir da compreensão de Maurice Tardif ${ }^{25}$. Para o autor, existem três orientaçóes fundamentais. A primeira caracteriza a cognição, mais desenvolvida pela psicologia cognitiva e suas derivaçóes no construtivismo; a segunda diz respeito à "vida dos professores" (p. 232), amparadas mais pela fenomenologia existencial e pela psicanálise; já a terceira leva em consideração as "categorias, regras e linguagens sociais que estruturam a experiência dos" professores. Continua o autor, afirmando que as três dimensóes não são impermeáveis e trocam entre si, tornando a questão da subjetividade rica e complexa. 


\section{Resultados e discussão}

Inicialmente, destaco as falas a respeito da formação profissional de cada um, da escolha pela profissão, sobre as diferenças entre as formas de abordagem e entendimento da EF, etc. Tais discursos apresentam-se fundamentais para que identifiquemos seus perfis profissionais:

"minha formação foi toda tecnicista. A partir do momento que eu ingressei na escola, a minha cabeça mudou em relaçáo ao tratamento com o aluno, então no clube eu tinha um pensamento tecnicista e na escola era mais de corporeidade, de movimento, com mais relação de respeito ao indivíduo, com as diferenças" (PF).

"A minha vida inteira eu sempre estive voltado para o esporte e para a atividade fisica e isso me levou a fazer o curso. Hoje eu estou trabalhando na EF escolar e a gente trabalha a parte esportiva, os esportes na escola, o futebol, o voleibol, o basquetebol, a parte da criança, a EF do lazer, de brincadeiras, de jogos, sem competição e sem visar o aspecto fisico" (PE).

"A EF não estava nos meus planos iniciais [...]. Mas quando eu era [jovem], eu sempre falava que ia dar aula para criança [...]. Ai fui fazer vestibular por eliminação e vi que EF podia ser uma boa, pois eu tinha uma identificação com a Ginástica olimpica. Eaí já tinha aquele gosto por dar aula... e foi assim" (PM).

De imediato, percebi claramente a influência esportiva sobre as decisóes dos entrevistados na escolha do curso superior, reflexos de uma EF essencialmente técnica, "filha bastarda" da modernidade. Mas, simultaneamente, julguei que estava diante de professores que buscavam formas diferenciadas e críticas de elaborar aulas na escola, no tratamento com seus alunos, na avaliação e busca de objetivos, em comparação às suas histórias voltadas essencialmente para a esportivização, para a técnica.

Contudo, iniciando o debate sobre a questão central do trabalho, perguntei:

Como você compreende, de um modo geral, o processo de avaliação na escola? (E).

"Eu acho que a gente tinha que ter o peso e altura pra gente ver o desenvolvimento de crescimento do aluno. Esse é um método que eu acho que deve ser feito. Outras formas de avaliar eu acho que ninguém testou até hoje" (PF).

"Eu vou te responder pensando no lado do aluno. $O$ aluno quando não tem uma nota, ele não fica preocupado quanto a uma participação ou não. Ele está preocupado com a nota [...]. Então, eu acho que isso menospreza um pouquinho a nossa área" (PE).

"Eu acho engraçado porque eu estou tentando lembrar de tudo que eu já li sobre avaliação até agora. Mas assim... é um sistema que a gente tem, né? E sempre teve, desde o início... eles mostram lá pela nota, naquele momento, o que aprenderam sobre o que o professor está perguntando. E eu acho que nesse sentido, para a gente $[\mathrm{da} \mathrm{EF}]$ é melhor... para mim é melhor. Porque eu näo tenho como avaliar o meu aluno nesse sistema de nota. [...] A gente não precisa dessa pressão [sobre o aluno]"(PM).

Nesse momento as ambivalências foram claras e evidenciou-se o caráter subjetivo, relacionado aos desejos, às angústias e idiossincrasias de cada um. Considerando que os entrevistados não responderam a questão pedida de forma objetiva, a qual tratava de uma visão mais ampla a respeito do processo de avaliaçâo dos alunos na escola, eles denunciaram suas dúvidas sobre como pensar criticamente o processo e pareceram pouco à vontade, desconfortáveis, por não conseguirem elaborar uma reflexão concatenada sobre a avaliação. Ressalto que os recortes em destaque foram as primeiras frases ditas, o que revelou uma formação profissional aligeirada e com lacunas, no que tange à compreensão sobre a avaliação pedagógica escolar.

$\mathrm{Na}$ fala do professor estadual, ficou nítido o descontentamento pelo fato da EF não possuir valorização por não ter um processo avaliativo reconhecido. Ele associou diretamente a valorização da área à preocupação dos alunos com as notas. É como se a EF devesse causar certa tensáo negativa no indivíduo para encontrar o seu reconhecimento social (como Ciência). Assim, a pressão regulatória exacerbada na modernidade, e narrada a partir de SAnTos ${ }^{9}$, surge com clareza nessa passagem. Se para o autor, os excessos regulatórios da vida social vêm dilacerando o cidadão comum ao longo da modernidade, não é demais compreender que os exageros regulatórios da vida escolar massacram os atores escolares, podendo contribuir, inclusive, para o 
que eu chamaria de alienação regulatória do professor. SANTOS $^{8}$ nomearia o processo por "microdespotismo do trabalho" (p. 109), ou seja, o docente não fica à vontade ao lidar com alunos que experimentam uma "EF não-regulada", desprovida das notas e, por isso, precisa de uma "coisa" - a nota - para gerenciar o "conforto" da relação (de poder). Perrenoud ${ }^{2}$ contribui afirmando que

[no] ensino obrigatório, a relação pedagógica é frágil, de modo que avaliação certificativa, com seus mecanismos de êxito e de fracasso, de orientação e de seleção, parece um modo de pressão indispensável. [...] Esses professores não desejariam, portanto, de modo algum ater-se a uma avaliação formativa; para eles, é uma questão de status e de sobrevivência na relação pedagógica (p. 163).

Já o professor do munícipio, apesar de revelar seu distanciamento da literatura, apresentou forte crítica ao sistema avaliativo numérico, argumentando que não há como avaliar alunos por meio de notas específicas. Destaco sua conclusão: "A gente não precisa dessa pressão [sobre o aluno]", o que revelou nítido descontentamento com o uso excessivo das notas. Perrenoud ${ }^{2}$ completa, e explica que a nota não traduz o que o aluno de fato sabe ou mesmo aquilo que o professor não tenha ensinado, mas representa uma referência, uma lembrança (aos dois) sobre o que pode vir a acontecer com a aproximação do fim do ano.

A ideia também me leva a outra reflexão: a ausência de métodos avaliativos quantitativos na EF seria uma opção segura para a valoração de suas questóes pedagógicas específicas relacionadas à cultura corporal? Caminharíamos assim, na direção do conhecimento-emancipação defendido por Santos?

Apesar das ambivalências presentes nas falas dos entrevistados, aprofundei a discussão sobre a avaliação especificamente na EF escolar e verifiquei alguns pontos que representam comprometimento com a profissão docente:

Como você compreende o processo de avaliação na EF escolar?

"Eu acho que muito de forma individualizada [...] porque quando eu comecei a fazer avaliação aqui [na escola], que a gente precisa de rendimento [esportivo] [...] eu fazia velocidade, teste de Cooper, impulsão vertical, horizontal e sempre fiz estatistica disso e jogava no Excel e tentava aumentar a performance desses meus alunos [...]. Hoje eu faço peso e altura" (PF).
" ão existe a avaliação formal, porque a avaliação na EF é feita em conceitos. A gente tem o conceito $A, B e C$ [de acordo com a participação]. Então a avaliação na minha realidade não existe. Não tem notas, é feita em conceitos e é difícil de mensurar isso, para dar uma avaliação formativa" (PE).

"Eu estou avaliando o tempo todo. [...] Mas não acho que faz sentido [conceituar] por conta da especificidade que [tem] a nossa disciplina. [...] E não é por conta da subjetividade, porque isso dá a impressão ser uma coisa muito aberta... e não é. Eu tenho meus conteúdos e meus objetivos [...] Eu quero ver se ele vai conseguir rebater a peteca [...]. E eu acho que isso náo é subjetivo, é uma coisa bem concreta. [...]. Como eu vou dar um conceito $C$ para um aluno que ainda não conseguiu entrosar e controlar o corpo dele? [...] Isso nunca fez parte do meu objetivo enquanto professora... dar uma nota para o aluno. [...] E eu não acho que eu tenho que legitimar a minha disciplina por uma avaliação" (PM).

Antes de apresentar minha interpretação sobre cada resposta, informo que todos os professores apresentaram claras dificuldades para conceituar ou definir sua compreensão do processo de avaliação na EF escolar. Não houve uma "única" lógica (coerente) entre os critérios e cada um deles pareceu seguir caminhos próprios sobre o que deve ser feito, ensinado ou avaliado. Não houve ainda referência ao currículo ou ao projeto político pedagógico de cada escola, ou mesmo alguma relação com qualquer documentação referencial que orientasse uma prática de intencionalidade avaliativa.

$\mathrm{Na}$ escola federal, por exemplo, o professor apresentou a ideia de desempenho esportivo por meio da racionalização e da técnica, ou seja, um modelo ainda controlado. A reprodução da prática hegemônica é visivelmente destacada e assumida pelo docente que afirmou: "a gente precisa de rendimento [para competir]". Perrenoud ${ }^{2}$ contribui e explica que a avaliação formativa está inserida numa pedagogia igualitária, mas isso não parece ser suficiente para banir o espírito de competição das aulas, pois os professores e a escola estão inseridos num sistema competitivo: a modernidade regulatória. Urge assim, repensarmos os modelos de gestão da educação para além da rivalidade. Conforme o autor ${ }^{2}$, "é preciso ter uma fé e uma força consideráveis para se privar destes motores formidáveis que são a competição, o desejo de ultrapassar os outros, de se distinguir;" (p. 136). Não é demais lembrar que tal questão 
é amplamente estudada e debatida pelos grupos acadêmicos da EF que "pensam a pedagogia", mas com o exemplo, evidencia-se o distanciamento das pesquisas sobre EF escolar do cerne da própria escola a partir do Movimento Renovador do campo ${ }^{1}$.

A postura dos professores do estado e do município, entretanto, já possui maior proximidade. Para eles, a EF não precisa de avaliaçôes técnicas, devido às subjetividades do processo, o que me parece revelar maior compromisso e responsabilidade com a formação dos discentes. Ainda que não sistematizadas num modelo moderno, diferentemente do professor federal, ambos apresentaram preocupação com qualidade. Observe-se, por exemplo, o termo "avaliação formativa" (e não certificativa), dito pelo professor estadual, e ainda, as afirmaçôes: "Eu estou avaliando o tempo todo" e "não acho que eu tenho que legitimar [valorizar] a minha disciplina por uma avaliaçáa”", ditas pelo professor municipal. Sáo termos, inclusive, que merecem destaque por apresentar clara similaridade com expressões vistas na literatura pertinente ao assunto, o que denota que os dois docentes possuem crítica sobre o processo.

As tentativas de esclarecimento, mesmo que afastadas de uma elaboração mais teórica, me parecem argumentos plausíveis contra as exigências burocráticas avaliativas que, por vezes, não fazem sentido na EF escolar. Nos casos, evidenciamse práticas de aplicação de notas/conceitos que não representam a realidade do processo ensino/ aprendizagem e é exatamente essa forma burocrática que os desgasta, pois a avaliação ocorre, mesmo não sendo possível quantificá-la. Como defendeu o entrevistado do município: "Eu tenho meus conteúdos e meus objetivos [...] Como eu vou dar um conceito $\mathrm{C}$ para um aluno que ainda náo conseguiu entrosar e controlar o corpo dele?". SANTOS ${ }^{8,9}$, assim como TARDIF ${ }^{25}$, sustentam que nossas trajetórias de vida, nossos valores e nossas crenças são a prova íntima do nosso conhecimento, o que permite afirmar que as significaçóes e sentidos do conhecimento estão ancorados à nossa história. Será demasiado acreditar que os demais professores de EF de cada escola visitada possuem práticas semelhantes aos colegas? Não serão as instituiçóes modernas, dotadas de um poder que busca homogeneizar práticas? Elementar: os professores mais críticos sabem que sistema imposto objetivamente não dá conta dos sujeitos envolvidos, da dinâmica das aulas e do que a EF é capaz de proporcionar.

Observei na próxima fala o procedimento de avaliação exercido pelo professor da escola federal.
Nesta escola, os demais professores de EF parecem apenas "prestar contas" ao sistema (moderno) inquisidor. Eles reconhecem a impotência da avaliação, mas se submetem ao sistema. Observemos esta pergunta, a qual surgiu no debate devido à naturalidade das conversas:

"Você avalia seus alunos na EF escolar? Pois, institucionalmente, eu suponho que você tenha que prestar contas à escola, preencher diários, colocar um conceito, certo?” (E).

"Bom... nós estamos testando [as avaliaçóes de Bloom] aqui já tem uns 03 anos. Nós temos a frequência, vamos supor, de 10 pontos no total, a frequência equivale a $70 \%$ e os 03 dominios recebem um ponto para cada um deles, que säo os restantes 30\%. O cognitivo é a habilidade dele no futebol, na natação, no basquete. No afetivo ése ele integra bem com os colegas [...]. Mas nem todo mundo leva a sério este tipo de avaliação. Chuta uma qualquer para dizer que fez" (PF).

"Na realidade não [...] eu avalio a presença e a participação do aluno nas aulas. Formalmente, eu não avalio a questão propriamente dita. [...] Eu dou 32 aulas semanais e tenho quase 40 alunos em cada turma, ai para todos serem avaliados objetivamente é complicado. É tudo bem mais subjetivo mesmo. Preencho os diários com presença e participação" (PE).

"assim, de fazer gráficos, classificaçóes $A, B$ ou $C$, bom, médio ou ótimo, não. Eu apresento meus diários só com presença ou ausência e isso foi decidido dentro da escola pela maioria dos professores" (PM).

Abordando a resposta do professor da escola federal, questiono: o que será a seriedade avaliativa para ele? Será apenas atribuir números ou letras a aspectos subjetivos? Será a formalização do processo que possui o verdadeiro valor? E para os demais que também lá trabalham? Que pensar sobre a expressão: "Chuta uma [avaliação] qualquer para dizer que fez", que parece advir dos seus colegas de trabalho? Fica evidente a tentativa de regulaçáo e burocratização da área, tentando legitimá-la falsamente no âmbito escolar. No caso observado, não é importante a questão formativa, mas apenas apresentar algo escrito, controlado, nomeado, classificado, ordenado, rotulado - ainda que levianamente - visando atender aos padrôes de exigência modernos. 
SANTOS ${ }^{8,9}$ argumenta sobre o conhecimento prudente para uma vida decente, afirmando que, na contemporaneidade epistemológica, deveria ser menos importante $\mathrm{o}$ ato de controlar e classificar, pois o foco deveria centrar-se no compartilhamento do conhecimento. $\mathrm{O}$ autor advoga por uma prudência diante de um mundo domesticado pelas regulaçóes e aponta a precariedade de sentidos de vida, mesmo em contextos onde a sobrevivência parece garantida (não é demais lembrar ao leitor que trato aqui de professores estabilizados). No mesmo sentido, completa GATTi ${ }^{16}$, elencando pontos necessários para um bom desenvolvimento da avaliação, dentre os quais destaco:

(1) Preparação adequada nos sistemas, nos diferentes níveis gestores, nas escolas e suas equipes. Criar um clima não persecutório e de fundo punitivo, mas sim, uma cultura de crescimento profissional continuado. (2) Formação de lideranças expressivas que possam dar ao processo um sentido adequado, não ameaçador, mas sim, pedagógico. (3) Criação de um clima de sinceridade. [...]

(5) Propiciar a criação de clima de abertura para aspectos problemáticos. [...] (9) Levar em conta diferenças locais, regionais, culturais (p. 381).

Avançando na análise da fala do PF, a situação descrita pode ser interpretada como uma busca pelo almejado status científico da EF, pois para tais professores, a ancoragem de "notas ou conceitos" parece contribuir para a fundaçáo de estruturas, "muros" que funcionam como fronteiras, que delimitam seu espaço de atuação epistemológica e profissional. Perrenoud ${ }^{2}$ explica que muitos professores não têm, necessariamente, a vontade de avaliar e classificar, mas sim "encontrar certas satisfaçôes pessoais, inclusive narcísicas e relacionais, no exercício de sua profissão" (p. 158). Ora, os docentes sabem que as notas não são confiáveis, mas parece existir nelas um poder, do qual muitos deles não conseguem abrir mão.

Ainda sobre a escola federal, observemos que a EF recebe uma quantificação percentual de $70 \%$ referente à presença do aluno nas aulas. Os demais $30 \%$ são atribuídos aos três aspectos das teorias de Bloom. Em síntese, o aluno não precisaria fazer nada se apenas assistisse a todas as aulas, pois já estaria aprovado só por estar lá. Em segundo lugar, e além de verificar que o professor não soube explicar o que significa um processo cognitivo, relacionando-o ao desenvolvimento motor das temáticas esportivas, e que ele avalia seus alunos afetivamente pela integração com os outros (fico pensando na angústia dos tímidos), percebo claramente não existir qualquer preocupação avaliativa sobre a compreensáo da cultura corporal. Mas se a escola e o professor almejam, de fato, uma sistematização da avaliação em EF, a burocrática Taxonomia de Bloom não me parece ser a referência mais apropriada. Ora, onde ela se encontra referendada nos documentos da área?

Neste momento, percebi ainda ambivalência (desconforto) nas falas, expressas pelo "incômodo" dos professores do Estado e Município, por reconhecerem que não seguem critérios estipulados nos documentos (modernos), considerando que estes, naturalmente, não podem representar o alcance subjetivo que as práticas da EF possuem. É como se surgisse uma tensão específica ao se depararem com o dilema ético: seguir os documentos oficiais ou o próprio reconhecimento de que os documentos náo têm representatividade ou sentido? Essa luta interna que vivenciam, a qual é traduzida no discurso, e as críticas que fazem sobre as fragilidades próprias do processo avaliativo na escola, me parecem reflexos de posturas responsáveis.

Ressalto que as escolas do âmbito federal e municipal não possuem seus respectivos documentos publicados para domínio público até a presente data (abril de 2016). Contudo, a partir de contato realizado por e-mail com o Departamento de Planejamento Pedagógico e de Formação da Secretaria de Educação da cidade, recebi a informação de que "não foi possível concluir o documento [de EF] no final de 2012, quando todas as outras áreas finalizaram seus textos. Houve uma pequena interrupção e o trabalho foi retomado por outra equipe em 2014", o que revela, para além do seu andamento, a própria negligência, refletida na morosidade com o processo referente à EF. No âmbito estadual, por sua vez, os Conteúdos Básicos Comuns de $\mathrm{EF}^{27}$, publicados há mais de 10 anos, abordam a temática "avaliação". Entretanto, o documento não foi sequer citado pelo(a) entrevistado(a).

Há outro ponto que se destaca, pois as narrativas dos professores do estado e município parecem se completar. É assumida a impossibilidade de avaliar os alunos e eles reconhecem não realizar avaliaçóes objetivas. Agregue-se que, o fato do professor federal apresentar uma tentativa de sistematização utilizada em sua escola, também não torna o caso táo distante dos demais. Em todos eles, evidenciam-se a ausência de critérios e de instrumentos que possam colaborar para uma avaliaçáo formativa mais segura e que promova maior desenvolvimento dos discentes. 
De acordo com o histórico trabalho do Coletivo de Autores ${ }^{1}$, muito pertinente nesse momento, a classe deveria buscar a

superação de práticas mecânico-burocráticas (aplicar testes, selecionar alunos, dar notas, detectar talentos) pela busca de práticas produtivo-criativas e reiterativas, que possibilitem 'mobilizar plenamente a consciência dos alunos, seus saberes e suas capacidades cognitivas, habilidades e atitudes para enfrentar problemas e necessidades, buscando novas soluçôes para as relaçóes consigo mesmo, com os outros e com a natureza (p. 104).

Ao final do diálogo, os entrevistados responderam sobre o seguinte questionamento:

"Nos últimos anos, parece ser um entendimento comum a percepção de que os alunos estão se afastando das práticas de EF na escola. Você considera que isto esteja ocorrendo? Em caso afirmativo, a quais motivos você atribui tal evasão?" (E).

"Pode ser culpa do próprio professor que não se envolve com a disciplina, [...] pode ser do aluno também preocupado com o futuro profissional dele na faculdade, e ele está atrás de nota. Pode ser também falta de apoio da instituição [...] por julgar a EF uma submatéria [...]" (PF).

"Eu concordo em termos. Porque quanto [mais novos] eles são, mais participação eles têm na EF. A partir da adolescência a participação é menor. E eu acho que é por causa da estética de não ficarem suados para os outros horários [...]. Pode ser também por falta da gente mesmo [os professores] não incentivar, não procurar outro caminho que não seja o esporte dentro da área da $E F "(\mathrm{PE})$.

"isso não é de hoje, sempre foi assim... vai chegando $7^{\circ}, 8^{\circ}, 9^{\circ}$ ano... é o momento [...] dos interesses outros, entendeu? [...] Mas eu acho também que no ensino médio os professores são meio largados, sabe? Assim, de conteúdo... essa é a impressão que trago da época que eu dava aula no médio. [...] É a falta de responsabilidade do professor, porque os alunos precisam ser estimulados o tempo todo" (PM).

Eu tinha a intenção de verificar se os alunos se afastavam da EF por motivo de avaliaçóes em outras disciplinas. Não obstante um dos entrevistados tenha apresentado o argumento sobre a busca de notas, observei que ele não foi o principal. Em todas as falas, as responsabilidades sobre a evasão discente são atribuídas aos próprios docentes da área que, em geral, parecem não estar preocupados ou engajados na realização da profissão, ou mesmo na busca por alternativas pedagógicas fora da esportivização, e que poderiam despertar maior curiosidade nos alunos.

Assim, permito-me aqui um rápido "desvio", pois se torna pertinente destacar recente pesquisa ${ }^{28}$, argumentando sobre o "estado de desinvestimento pedagógico" da categoria. Nas palavras dos autores, diante da condiçãao de "segunda classe" da EF na cultura escolar, vê-se provocado nos professores da disciplina um sentimento de rebaixamento, quer dizer, eles não mais concebem a si mesmos como sujeitos de valor igual aos demais membros da coletividade da escola. A repercussão disso é perceptível náo somente no processo de construçấo da identidade desses docentes, mas também em sua prática pedagógica e na dinâmica curricular como um todo (p. 127-8).

A postura denunciada parece uma posição de cansaço, ou mesmo de acomodaçáo. Nos três relatos, os docentes responsabilizaram a própria classe pela evasão dos alunos. Fica-me, assim, a forte sensação de que parte deles desiste da busca por reconhecimento ou, simplesmente, abdica de lutar e permanece na situação paralisante de rebaixamento passivamente tolerado $^{28}$. Ao final da entrevista com o professor municipal, percebi forte tom de melancolia em sua fala: "Eu tinha vontade de fazer muito no início, lá atrás sabe? Mas agora nem tanto". Ora, desgastados pelas vexatórias condiçóes de trabalho, pelo processo burocrático avaliativo desprovido de sentido, pela perspectiva neoliberal de educação, pela herança filosófica da modernidade de valorização cognitiva em detrimento da corporeidade, pela negligência dos modelos de gestão atual sobre a importância da EF, parece-me difícil mesmo observar aspectos motivacionais mais significativos nos professores da área.

Sobre a relação do tema quantificação por notas com o desprestígio que a área sofre pelos próprios docentes, acrescento ao lamentável quadro o sarcasmo de outros professores a respeito da imagem da EF no interior escolar. Para tal, apresento um breve relato de minha própria trajetória em uma escola que lecionei. Em certa reuniáo de Conselho de Recuperação de alunos, presenciei o desrespeito com o trabalho desenvolvido pela EF quando determinado(a) docente de outra área enumerou as notas de um aluno, quem tinha sua aprovação em 
julgamento. Todas as notas das demais disciplinas oscilavam entre quatro e cinco pontos. Ao final do relato, o(a) mesmo(a) docente citou, em forte tom de deboche, que apenas em EF o aluno havia tirado um dez.

Para além da insensibilidade irônica, destaco que a crítica foi oportuna. Claro que a nota dez não traduz uma realidade sobre o tal aluno em EF pelos inúmeros argumentos já expostos aqui, assim como as notas baixas nas demais disciplinas não significam incompetência ou ignorância da criança. O que pretendo questionar é se devemos insistir em levar a $\mathrm{EF}$ aos conflitos avaliativos mais pertinentes a outras áreas. Ora, os Conselhos de Recuperação têm se configurado como espaço intenso de disputa por poder e de categorização de alunos, muito mais do que num momento de reflexão sistemática sobre as práticas vivenciadas na escola, a aprendizagem efetiva ou a gestão do processo avaliativo. Enfim, no contexto citado, não podemos sequer defender a área diante da "provocação" feita pelo(a) docente. Se as avaliaçóes das demais disciplinas da escola moderna, conforme Perrenoud ${ }^{2,3}$, já são frágeis por excelência, as da EF também são, mas em escala ainda maior.

Em comparação com as demais disciplinas escolares, estas pelo menos possuem instrumentos e linguagens pertinentes a cada uma. Porém, no processo avaliativo de $\mathrm{EF}$ analisado nas três escolas, com professores dotados de larga experiência, reitero que não foi observada nenhuma relação com os currículos ou projetos políticos pedagógicos que norteiam os processos de ensino-aprendizagem nas instituições escolares, ou mesmo qualquer amparo por instrumentos específicos da área. Não percebi também posturas docentes voltadas para uma ampliação de mundo dos alunos, ainda que surgisse, em algumas falas, ambivalências e subjetividades que demonstraram haver "certa preocupação formativa". Sustento que os professores de EF, ainda que dotados de "boas intençôes", precisam compreender que os discentes vão para escola para descobrir experiências que os levem para além de suas vivências cotidianas ${ }^{29}$, e não só para jogar bola ou ensaiar coreografias.

Depreende-se ainda das entrevistas, que os docentes tendem a valorizar essencialmente o campo afetivo das relações em detrimento do cognitivo e/ou psicomotor das aprendizagens, o que parece oportuno para reiterar a importância da área na esfera axiológica, reforçando o potencial do campo para que germinem as ideias de Santos sobre a solidariedade. Há grande espaço para ela dentro da
EF escolar. Por outro lado, ao observar uma tentativa de sistematização técnica, os critérios utilizados foram pessoais, refletindo idiossincrasias e gerando como consequência a reprodução de hegemonias (caso do esporte de rendimento e a aptidáo física na escola federal).

Surgem inúmeras tensões que se desdobram do caminho até aqui percorrido: (1) o perigo do total abandono de critérios sistematizados que busquem realizar uma avaliação formativa voltada também para a crítica que, no caso da EF, tratase da compreensão das temáticas da "cultura corporal", as quais são previstas nos documentos oficiais do campo. Ora, se a atenção demasiada que se dá aos números é arbitrária, a sua ausência me parece igualmente problemática no sentido de uma aproximação com um tipo de "relativismo", o qual "justificaria" nada fazer; (2) os registros avaliativos dos professores de EF, que abordam somente o atitudinal ou o afetivo, parecem denunciar como eles valorizam a construçáo do conhecimento e a compreensão da "cultura corporal". Não avaliar revela o estado de desinvestimento pedagógico ${ }^{28}$ do docente? (3) A "cultura corporal" constitui-se como característica insular de objeto de estudo da EF. Logo, sustento não ser possível avaliá-la atribuindo-lhe números (notas de zero a dez ou conceitos A, B ou C). Reitero: que vem a ser cultura (corporal)? (4) Pressupondo, entâo, que qualquer prática da "cultura corporal" seja entendida como uma prática de sentidos e significados que envolve quem designa, quem produz e quem interpreta, e que possui ainda um crescimento indefinido e constante, os relatórios, diários ou provas não podem traduzir a intensidade, as emoçôes ou a beleza de um movimento corporal contextualizado a uma determinada prática da EF. (5) Exigir dos docentes de EF uma avaliação numérica e/ou conceitual parece reduzir nossa compreensão da escola a uma instituição voltada para a importância das palavras e dos números, em detrimento das atitudes, das práticas, do fazer e do realizar. Qual o espaço para a autonomia docente nesse contexto? (6) Como (re) pensar estratégias para o desenvolvimento de um processo criativo-avaliativo por parte dos docentes na escola, reinventando suas práticas e as próprias formas de avaliá-las? Na diversidade epistemológica contemporânea, isso não seria legítimo? Destaco aqui as singulares palavras de SILVA et al..$^{30}$ :

o movimento humano é uma prática de linguagem e o gestual seu signo; [...] a linguagem do movimento não possui organização analítica, 
de suscetível descrição rigorosa, mas organização poética, de construção criativa, fluida de comunicação; a interpretação do gestual não se dá na análise formal dos pedaços, mas na inteireza das relaçôes e na produção de significado para o sujeito da ação (p. 117).

Isto posto, sustento que a sensibilidade pertinente às relaçóes que envolvem práticas corporais e avaliaçóes potencialmente subjetivas, principalmente no campo da estética e da aquisição de valores vinculados à ideia solidária que envolve os jogos, apresenta condiçôes que contribuem para o desenvolvimento social e emocional dos discentes na escola e dispensa os controles burocráticos já debatidos aqui. Reitero a ideia de SANTos ${ }^{8,9}$ ao considerar o conflito entre regulação burocrática e emancipação social (dois pilares modernos), como uma das principais causas que gerou a crise da modernidade (considerando que o período acentuou o lado da regulação). Ora, a modernidade prometeu alguns contrapontos, por isso precisamos reinventar algumas práticas. Ela negou a validade daquilo que não conseguiu cumprir e tornou objetivo (a norma) aquilo que cumpriu. Seu projeto incompleto torna ainda mais robusto o pilar das regulaçóes e aniquila a promessa do pilar da emancipação. Não creio, portanto, ser demasiado sustentar que, sem as notas que ainda perpassam as avaliações tradicionais da EF nos formatos observados, abrir-se-ia mais espaço para a compreensão e desenvolvimento do processo solidário, objetivo essencial na busca por humanização. Conforme Perrenoud ${ }^{2}$,

a avaliação pedagógica tradicional é um jogo de gato e rato, um confronto de estratégias e de contra estratégias. É muito difícil, nestas condições, criar uma relação verdadeiramente cooperativa entre professores e alunos, porque uma hora ou uma semana depois, os primeiros vão julgar os segundos, às vezes com rigor. Aliás, é por isso que é difícil conjugar, na mesma relação pedagógica e no mesmo espaço-tempo, avaliação formativa e avaliação certificativa: a primeira supóe transparência e colaboração, ao passo que a segunda se situa no registro da competição e do conflito e, consequentemente, do fingimento e da estratégia (p. 70).

Para o autor ${ }^{3}$, a progressáo das aprendizagens deve ocorrer por balanços periódicos das aquisições dos alunos, os quais "deveriam confirmar e aprimorar o que o professor já sabe ou pressente. Portanto, não dispensam uma observação contínua, da qual uma das funções é atualizar e completar uma representação das aquisiçôes do aluno" (p. 49). E ainda, se desejamos desenvolver imaginação, cooperação, expressão [corporal], raciocínio, argumentação, entre outros, não podemos acreditar em progressos significativos em pouco tempo, fato que me leva a questionar também a retenção (reprovação) em EF.

Assim, a avaliação formativa em EF não necessita ser padronizada e burocratizada, pois ela inscreve-se na relação diária entre o professor e os seus alunos, e seu objetivo é auxiliar cada um a desenvolver-se no seu tempo. Sustento ainda, como opção significativa, reforçar uma prática que me parece pouco realizada no contexto da EF escolar: a autoavaliação. Para SACristán e Gómez ${ }^{31}$, essa é uma forma de responsabilizar o aluno "em seu próprio processo de aprendizagem ou porque se pretenda avaliar algum aspecto que só ele pode conhecer" (p. 319). Se os autores sustentam tal prática como democrática e mais ligada às qualidades pessoais e sociais, em detrimento das mais essenciais, como as acadêmicas, creio que sua utilização seja oportuna diante do ato de avaliar a cultura corporal na EF, considerando seu distanciamento da ciência moderna. Isso colaboraria com o desenvolvimento do conhecimento-emancipação e a solidariedade, ambos propostos por Santos.

Toda argumentação exposta até aqui, conforme também explicam Vargas e Moreira ${ }^{6}$, leva-me a refletir sobre a necessidade de novos modelos de gestão da Educação e da EF escolar, os quais, mais do que voltados para a busca de resultados, desempenhos e eficiência, se pautem no sentido de fortalecer o profissionalismo dos mestres, visando a um trabalho docente autônomo, criativo e crítico, o que refletiria sobremaneira nas relaçóes de ensino/ aprendizagem com os discentes.

Mas para que haja um avanço concreto, sustento ainda existir uma tensão fundamental, a qual precisa ser superada pela categoria de docentes de EF: a necessidade de atribuir status à área por meio de avaliaçóes certificativas. $\mathrm{Na}$ EF escolar, somos livres de amarras lógico-racionais, mas por vaidade intelectual, alguns segmentos profissionais do campo parecem buscar incansavelmente uma legitimidade por meio da quantificação e do controle; uma falsa identificação com um status científico moderno que a EF, suponho, nunca oferecerá; e que nos prenderia a grilhóes já rompidos por nossa essência de relaçóes subjetivas com a cultura corporal. Assim como em outros campos de (re)conhecimento, como a Arte ou a Psicanálise, convivemos bem com a ausência 
da racionalidade moderna, e isso não significa irracionalismo, mas liberdade de interpretação por meio de uma "lógica sensível".

Concluindo, e a despeito ainda, de acreditar que avaliamos o outro para mitigarmos também a nossa (in)consciência sobre a existência da exclusão, quero dizer, por (re)conhecermos o fato de que no mundo moderno não há "lugar" para todos, o que permanece talvez seja um desafio quase utópico - mas não podemos nos acovardar. SANTOS $^{8}$ afirma ser necessário uma busca profunda da compreensão das realidades que nos cercam, o quanto mais possível e, nesse caso, devemos buscar compreender os pormenores da realidade da EF escolar, para assim exercer essa utopia sem que a radicalidade da imaginaçáo seja nosso próprio obstáculo. Em outras palavras, é como o legado de Paulo Freire registrado em sua vasta obra, a qual tantas vezes nos mostrou que temos que lutar para tornar possível o que não parece possível, tarefa essa entendida como um constante redesenhamento do mundo.

\title{
Agradecimentos
}

À Fundação de Amparo à Pesquisa do Estado de Minas Gerais (FAPEMIG), pelo pagamento das bolsas de doutorado realizado no Programa de Pós-graduação em Educação da Universidade Federal de Juiz de Fora (PPGE/UFJF).

\begin{abstract}
Assessment in school physical education: tensions beyond epistemologies

The objective is to identify tensions that pervade the subject evaluation in Physical Education, highlighting contrasts and similarities between the practices of teachers. In the structure, has epistemological synthesis of Boaventura Santos, argues on the evaluation of the fragility based on modernity and presents literature review on the subject, questioning the bureaucratic way of its realization when dealing with the "body culture". In the discussion, using semi-structured interviews applied to three public school PE teachers, addressing their experiences in evaluation practice. Defines categories of analysis of content: ambivalence and subjectivity. It highlights six fundamental tensions and maintains that bureaucratic reviews impede knowledge-emancipation advocated by Santos. It concludes by highlighting the importance of axiological area size, positioning itself in favor of self-assessment as to promote student empowerment.
\end{abstract}

KEYwords: Body Culture; Knowledge; Modernity; School; Boaventura de Sousa Santos.

\section{Referências}

1. Soares CL, Taffarel C, Varjal E, Castellani Filho L, Escobar M, Bracht V. Metodologia do ensino da educação física. São Paulo: Cortez; 1992.

2. Perrenoud P. Avaliação: da excelência à regulação das aprendizagens: entre duas lógicas. Porto Alegre: Artmed; 1999.

3. Perrenoud P. 10 novas competências para ensinar: convite à viagem. Porto Alegre: Artmed; 2000.

4. Bracht V. Educação física e ciência: cenas de um casamento (in)feliz. 3a ed. Ijuí: Unijuí; 2007.

5. Fensterseifer P. A educação física na crise da modernidade. Ijuí: Unijuí; 2001.

6. Vargas CP, Moreira AFB. A crise epistemológica na educação física: implicaçóes no trabalho docente. Cad Pesqui. 2012;42(146):408-27.

7. Bauman Z. Modernidade líquida. Rio de Janeiro: Jorge Zahar; 2001.

8. Santos BS. Pela mão de Alice: o social e o político na pós-modernidade. 13a ed. São Paulo: Cortez; 2010.

9. Santos BS. A crítica da razão indolente: contra o desperdício da experiência. 8a ed. São Paulo: Cortez; 2011.

10. Santos BS. Um discurso sobre as ciências na transição para uma ciência pós-moderna. Estud Av. 1988;2(2):46-71. 
11. Santos W, Maximiano FL. Avaliação na educação física escolar: singularidades e diferenciaçóes de um componente curricular. Rev Bras Ciênc Esporte. 2013;35(4):883-96.

12. Oliveira IB. Boaventura \& a educação. 2a ed. Belo Horizonte: Autêntica; 2008.

13. Neira MG, Nunes MLF. Educação física, currículo e cultura. São Paulo: Phorte; 2009.

14. Sacristán JG. O currículo: uma reflexão sobre a prática. Porto Alegre: Artmed; 1998.

15. Luckesi CC. Avaliação da aprendizagem escolar: estudos e proposiçóes. $7^{a}$ ed. Sáo Paulo: Cortez; 1998.

16. Gatti BA. Avaliação e qualidade do desenvolvimento profissional docente. Avaliação. 2014;19(2):373-84.

17. Tenório KMR, Bezerra BB, Souza Júnior M, Gomes-da-Silva PN, de Melo MST. Propostas curriculares estaduais para educação física: uma análise do binômio intencionalidade-avaliação. Motriz. 2012;18(3):542-56.

18. Frizzo GFE. A organização do trabalho pedagógico da Educação Física na escola capitalista [tese]. Porto Alegre: Universidade Federal do Rio Grande do Sul; 2012.

19. Melo LF. Tecendo tramas sobre avaliação da aprendizagem em educação física escolar [tese]. São Paulo: Universidade São Judas Tadeu; 2011.

20. Ramiro FS. A avaliação da aprendizagem na educação física escolar de Ferraz de Vasconcelos [dissertação]. São Paulo: Universidade São Judas Tadeu; 2011.

21. Escudero NTG. Avaliação da aprendizagem em educação física na perspectiva cultural: uma escrita autopoiética [dissertação]. São Paulo: Universidade de São Paulo; 2011.

22. Vargas CP. Tensóes e desafios (pós-)modernos no campo curricular da educação física. In: Moreira AFB, Candau V, organizadores. Currículos, disciplinas escolares e culturas. Petrópolis: Vozes; 2014. p. 255-87.

23. Souza Júnior M. Práticas avaliativas e aprendizagens significativas em educação física: trajetória, orientaçóes legais e implicaçôes pedagógicas. Pro-Posiçóes. 2004;15(2):201-17.

24. Lovisolo HR, Borges CNF, Muniz IB. Competição e cooperação: na procura do equilíbrio. Rev Bras Ciênc Esporte. 2013;35(1):129-43.

25. Tardif M. Saberes docentes e formação profissional. Petrópolis: Vozes; 2002.

26. Bauman Z. Modernidade e ambivalência. Rio de Janeiro: JZE; 1999.

27. Minas Gerais. Secretaria Estadual de Educação. Conteúdo básico comum (CBC): educação física: ensino fundamental e médio. Belo Horizonte: SEE/MG; 2005.

28. Faria BA, Machado TS, Bracht V. A inovação e o desinvestimento pedagógico na educação física escolar: uma leitura a partir da teoria do reconhecimento social. Motriz. 2012;18(1):120-9.

29. Young M. O futuro da educaçáo em uma sociedade do conhecimento: o argumento radical em defesa de um currículo centrado em disciplinas. Rev Bras Educ. 2011;16(48):609-23.

30. Silva PNG, Cavalcanti KB, Hildebrandt R. A poética dos gestos dos jogadores. Rev Bras Cienc Esporte. 2006;27(2):105-19.

31. Sacristán JG, Gómez, AIP. Compreender e transformar o ensino. 4a ed. Porto Alegre: Artmed; 1998.

\section{Notas}

a. Parte desta discussão foi iniciada e desenvolvida em tese de doutorado em Educação defendida no Programa de Pós-graduação em Educação da Universidade Federal de Juiz de Fora (UFJF).

\author{
ENDEREÇO \\ Cláudio Pellini Vargas \\ Universidade Federal de Juiz de Fora \\ Rua José Lourenço Kelmer, s/n - Campus \\ Universitário \\ 36036-900 - Juiz de Fora - MG - BRASIL \\ e-mail: prof.pellini@yahoo.com.br
}

Recebido para publicação: 19/03/2015

$1^{\mathrm{a}}$ Revisão: 20/04/2016

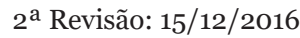

Aceito: 25/01/2017 